\title{
Determination of Onset of Action and Efficacy of Topical Lignocaine Anesthesia in Children: An In Vivo Study
}

\author{
Tejashri Gupte ${ }^{1}$, Urvi A Modi², Shreyas Gupte ${ }^{3}$, Ameya Sawant ${ }^{4}$
}

\begin{abstract}
Anxiety is one of the major issues in the dental treatment in children and needle is the most anxiety provoking armamentarium. For this reason, pediatric dentists are on a constant search to find more comfortable means for administering anesthesia. Topical anesthesia has proven to be a boon in this attempt. Literature shows that quite often there is little pain relief from topical anesthesia and one reason for failure may be that there is no consensus regarding the most appropriate time duration for topical anesthesia to anesthetize intraoral tissue prior to injection. Therefore, the aim and objectives of the study are as follows: (1) To determine duration for onset of action of lignocaine gel and lignocaine spray used as a topical anesthesia during local anesthetic infiltration in palatal area in pediatric patients. (2) To compare the efficacy of lignocaine spray and lignocaine gel in the same patient with bilateral injection. The study group consists of children in the age group of 6-12 years of both genders. Only those children who require palatal bilateral infiltration for their treatment, included in the study. A total of 120 children divided equally into 3 sub-groups depending on the amount of time gap between topical anesthetic application and local infiltration. (1) Group I-30 seconds (2) group II-1 minute (3) group III-3 minutes. Pain responses compared based on subject self-report using visual analogue scale to record subjective symptoms and sem (sound eye motor) scales to record objective symptoms. Results subjected to statistical analysis.
\end{abstract}

Keywords: Lignocaine, Topical gel, Topical spray.

International Journal of Clinical Pediatric Dentistry (2019): 10.5005/jp-journals-10005-1615

\section{INTRODUCTION}

Behavior management in pediatric dentistry is a challenge that comprises of various factors ranging from rendering painless dental care to improving treatment acceptance by a child. One major hindrance to a stress-free dental treatment in children is anxiety and the "needle" is one of the major anxiety causing agents for both children and adult. Hence, pediatric dentists have a constant urge to find tools to avoid the pain of administering local anesthesia and find a more comfortable and pain-free method of administering anesthesia before dental procedures. Topical anesthesia has proven to be a boon in this attempt.

Multiple topical anesthetic agents are freely available today. Lignocaine is one of the commonly used anesthetic agents. Lignocaine is an amide local anesthesia with an exceptionally low incidence rate of allergic reactions and other adverse events. ${ }^{1}$ It is available in multiple forms such as gel, patch, sprays, and solutions. Most of the literature points out that many times there is a minimal pain relief, despite the use of topical anesthesia. One of the main reasons for failure may be that the dentist does not wait long enough after applying the topical anesthetic agent to allow the anesthetic effect to set in. ${ }^{2}$ In the past, several studies have focused more on the clinical effectiveness of various topical anesthetic agents rather than the effect of the onset of action. ${ }^{3,4}$ There is no consensus regarding the most appropriate time for a topical anesthesia to be left on the intraoral tissue prior to injection.

Therefore, the aim of this study is to determine the duration for the onset of action of lignocaine used as a topical anesthetic agent and the objectives were to determine the duration for the onset of action of lignocaine gel and spray used as a topical anesthetic agent during local anesthetic infiltration in the palatal area in pediatric patients. The study also aimed to compare the efficacy of lignocaine spray and lignocaine gel in the same patient with bilateral injection.
1,2,4 Department of Pediatric and Preventive Dentistry, Nair Hospital and Dental College, Mumbai, Maharashtra, India

${ }^{3}$ YMT Dental College and Hospital, Oral and Maxillofacial Surgery, Navi Mumbai, Maharashtra, India

Corresponding Author: Tejashri Gupte, Department of Pediatric and Preventive Dentistry, Nair Hospital and Dental College, Mumbai, Maharashtra, India, Phone: +91 9920055382, e-mail: tejashrigupte@ rediffmail.com

How to cite this article: Gupte T, Modi UA, et al. Determination of Onset of Action and Efficacy of Topical Lignocaine Anesthesia in Children: An In Vivo Study. Int J Clin Pediatr Dent 2019;12(3):178-181.

Source of support: Nil

Conflict of interest: None

\section{Materials and Methods}

The study was a randomized, split-mouth clinical study. Ethical clearance was obtained from the Institutional Ethics Committee. The study group consisted of children in the age group of 6-12 years of both genders attending the Department of Pedodontics and Preventive Dentistry. Informed consent was obtained from the parents of the study subjects and assent was obtained from children above 7 years of age prior to inclusion in the study.

Only those children were included in the study that required bilateral palatal infiltration for their treatment. Children who were classified as "positive" and "definitely positive" according to Frankl's behavioral rating scale were included in the study to avoid any bias in the response rate. Positive includes those patients that accept treatment at times cautiously and those who are willing to comply but at times with reservations. Definitely positive includes those patients who develop a good rapport with the dentist, takes an interest, laughs, and enjoys the treatment. Children with any allergic history to amide type of local

() The Author(s). 2019 Open Access This article is distributed under the terms of the Creative Commons Attribution 4.0 International License (https://creativecommons. org/licenses/by-nc/4.0/), which permits unrestricted use, distribution, and non-commercial reproduction in any medium, provided you give appropriate credit to the original author(s) and the source, provide a link to the Creative Commons license, and indicate if changes were made. The Creative Commons Public Domain Dedication waiver (http://creativecommons.org/publicdomain/zero/1.0/) applies to the data made available in this article, unless otherwise stated. 
anesthesia or children with pathology and inflammation of oral mucosa in the maxillary palatal region were excluded from the study.

A total of 120 children who required administration of local anesthesia in the palatal area for their dental treatment were randomly selected. They were divided equally into three subgroups depending on the time interval between topical anesthetic application and local infiltration. No control group was present in the study. Group I were those in which the time interval was 30 seconds. Group II were those in which the time interval was 1 minute and group III were those in which the time interval was 3 minutes.

The same dentist performed all examinations and treatments. Children were seated on a dental chair that was positioned to adequate light to facilitate application of the topical anesthetic agent at the desired site. Following isolation, the testing area was dried using a sterile gauze and, in each group, a topical anesthetic agent was applied prior to palatal local anesthetic infiltration. Sufficient care was taken to ensure that undue pressure was not exerted on the tissue during the application of the drug.

The topical anesthetic used was $2 \%$ lignocaine gel (Neon lab) on the left side and $10 \%$ lignocaine spray (Neon lab) on the right side. For the application of gel, calibrated $2 \mathrm{~mL}$ syringes were back loaded with the test agent and $0.2 \mathrm{~mL}$ of the topical anesthetic agent was dispensed for application on the palatal site with a cotton tip applicator and for the application of spray form, one puff of spray was used for each subject for the purpose of standardization. The volume of lignocaine delivered in one spray was $10 \mathrm{mg}$. After the designated wait, local infiltration anesthetic administration was carried out. A new 25 gauge needle (DENTSPLY) was used for each insertion. The local anesthetic administered was $2 \%$ lignocaine (Themis). Pain responses were compared based on the subject self-report using visual analogue scale (VAS) to record subjective symptoms and sound eye motor (SEM) scale was used to record objective symptoms.

\section{Statistical Analysis}

Comparisons of the proportion of gender distribution in the study groups were done using the Chi-square test. One-way analysis of variance (ANOVA) was used to compare the means of ages among the three groups. The paired $t$ test was used to determine the difference in the efficacy of lignocaine gel and lignocaine spray.

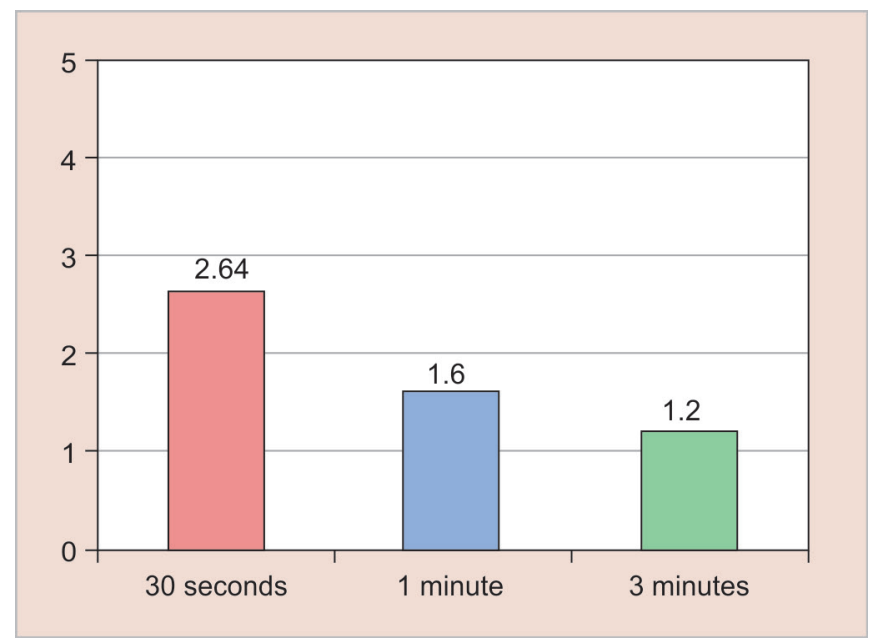

Fig. 1: VAS score after application of lignocaine spray

\section{Results}

A majority of the patients in groups I and II were males (52\% and $60 \%$, respectively). In group III, a majority of the patients were females (60\%). The gender distribution of the studied population was not significant $(p=0.8139)$. The age of the studied population was in the range of 6-12 years. The mean age of the whole population was 8.14 years. The average age of group I was more as compared with the other two groups. On application of lignocaine spray, the VAS score was found to be reduced after 1 minute (1.6) and 3 minutes (1.2). After 30 seconds, it was (2.64) (Fig. 1). The SEM score was found to be decreased after 1 minute of topical application of lignocaine spray. The score increased after 3 minutes to (3.6) which was lower than 30 seconds score (4.68) but higher than 1 minute score (3.4) (Fig. 2). The VAS score was found to be reduced with time after application of lignocaine spray. It was decreased from 3.48 to 2.6 and 2.4 after 1 minute and 3 minutes, respectively (Fig. 3). On application of lignocaine gel, the SEM score was reduced after 1 minute (4.6). It remained the same after 3 minutes (4.6) (Fig. 4). In all the groups, VAS scores were higher in patients treated with lignocaine gel as compared to lignocaine spray. This difference was found to be statistically significant in all the groups according to the paired $t$ test (Table 1). In all the groups, SEM scores were higher in patients treated with lignocaine gel as compared with lignocaine spray. This difference was found to be statistically significant in groups I and III according to the paired $t$ test (Table 2).

\section{Discussion}

Injections are the biggest cause of anxiety during a dental appointment. ${ }^{5,6}$ Anxiety is a significant factor resulting in to avoidance of dental care by some patients, especially children. ${ }^{7}$ Circumventing this fear makes the experience much more comfortable for the patient and allows the pediatric dentist to provide the best standard of the care for the child.

The use of topically applied anesthetics is an important component for atraumatic administration of local anesthetics. There are several studies in medical literature that compare the efficacy of different topical anesthetic agents. ${ }^{8,9}$

Gill and Orr in their study of comparing different topical anesthetics have questioned about the actual efficacy of topical

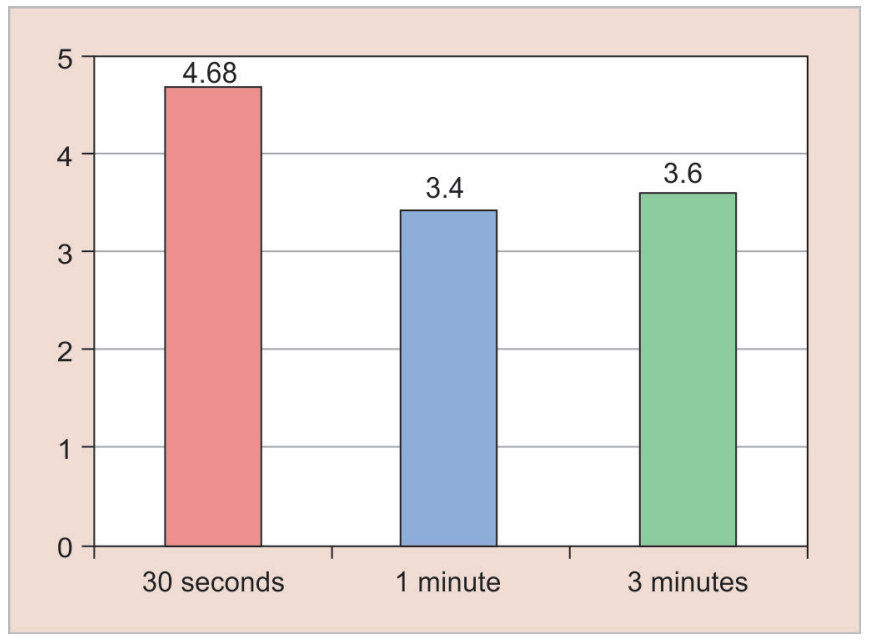

Fig. 2: SEM score after application of lignocaine spray 


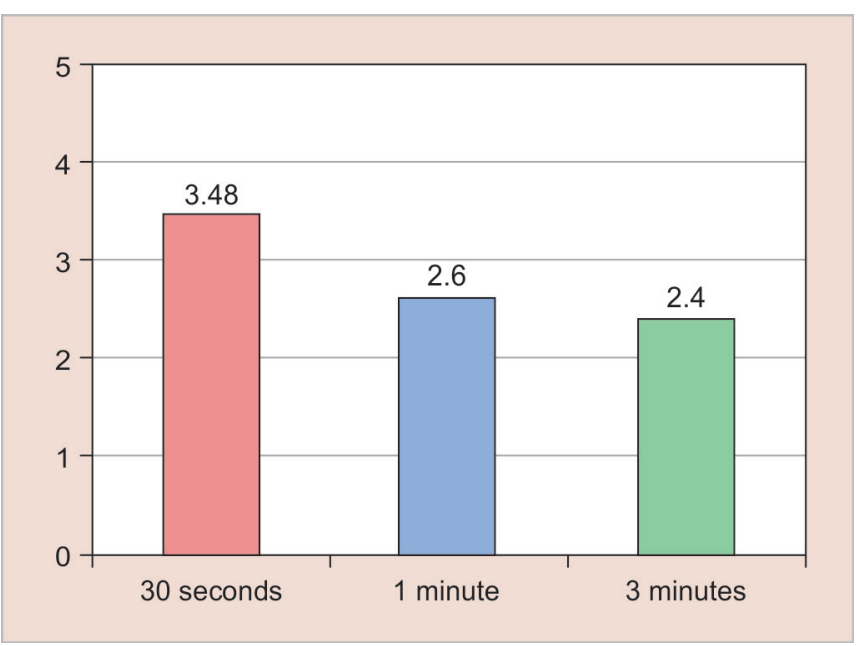

Fig. 3: VAS score after application of lignocaine gel

Table 1: Comparison of efficacy of lignocaine spray and lignocaine gel (VAS scores)

\begin{tabular}{|c|c|c|c|}
\hline $\begin{array}{l}\text { Paired t test } \\
\text { (VAS score) }\end{array}$ & Group I & Group II & Group III \\
\hline$p$-value & 0.0026 & 0.0341 & 0.0039 \\
\hline$p$-value summary & $* *$ & * & $* *$ \\
\hline $\begin{array}{l}\text { Signif. different? } \\
(p<0.05)\end{array}$ & Yes & Yes & Yes \\
\hline $\begin{array}{l}\text { One- or two-tailed } \\
p \text {-value? }\end{array}$ & Two-tailed & Two-tailed & Two-tailed \\
\hline$t, \mathrm{~d} f$ & $\begin{array}{l}t=3.366 \\
\mathrm{~d} f=24\end{array}$ & $\begin{array}{l}t=3.162 \\
\mathrm{~d} f=4\end{array}$ & $\begin{array}{l}t=6.000 \\
\mathrm{~d} f=4\end{array}$ \\
\hline Number of pairs & 40 & 40 & 40 \\
\hline
\end{tabular}

anesthesia in reducing the pain. ${ }^{10}$ They had found that the analgesic effect of multiple different topical anesthetics was equivalent to a placebo. One of the reasons for these conflicting results in various studies could be due to failure in the standardization of the amount of the time a clinician should wait after application of the topical anesthetic and before administrating the local anesthesia. There is very meager mention about it in literature and, hence, the purpose

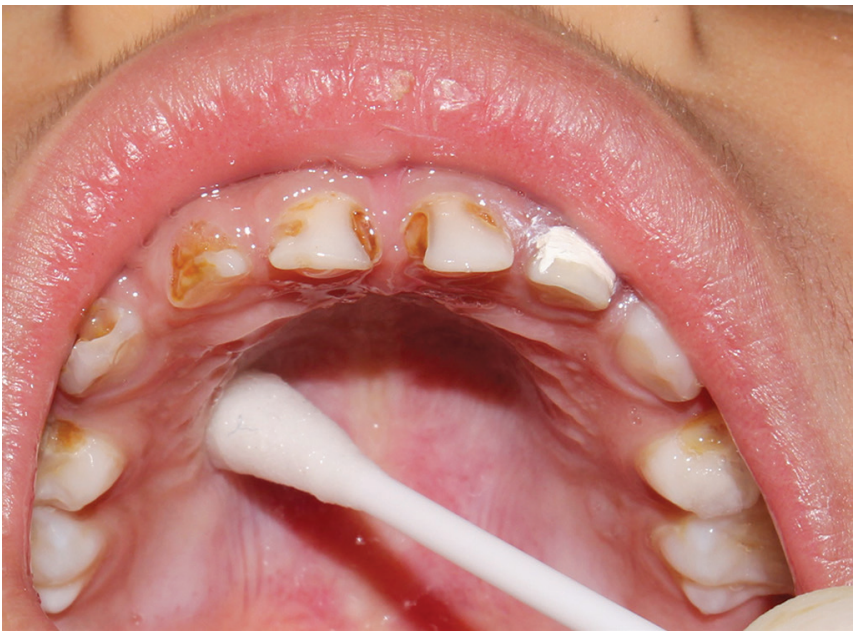

Fig. 5: Application of gel on the palate prior to local anesthesia administration

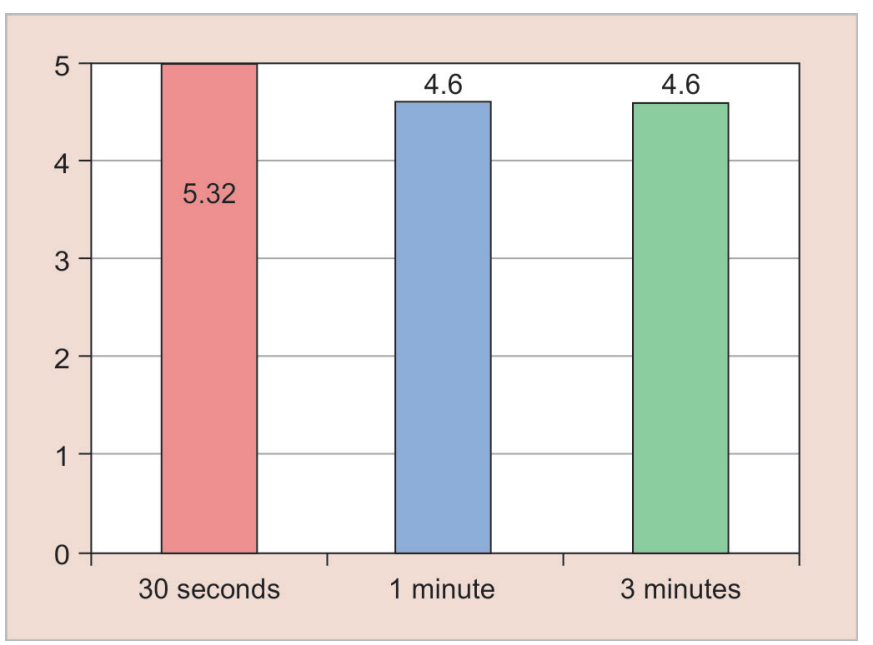

Fig. 4: SEM score after application of lignocaine gel

Table 2: Comparison of efficacy of lignocaine spray and lignocaine gel (SEM scores)

\begin{tabular}{|c|c|c|c|}
\hline $\begin{array}{l}\text { Paired t test } \\
\text { (SEM scores) }\end{array}$ & Group I & Group II & Group III \\
\hline$p$-value & 0.0293 & 0.0705 & 0.0341 \\
\hline$p$-value summary & * & Ns & * \\
\hline $\begin{array}{l}\text { Signif. different? } \\
(p<0.05)\end{array}$ & Yes & No & Yes \\
\hline $\begin{array}{l}\text { One- or two-tailed } \\
p \text {-value? }\end{array}$ & Two-tailed & Two-tailed & Two-tailed \\
\hline$t, \mathrm{~d} f$ & $\begin{array}{l}t=2.317 \\
\mathrm{~d} f=24\end{array}$ & $\begin{array}{l}t=2.449 \\
\mathrm{~d} f=4\end{array}$ & $\begin{array}{l}t=3.162 \\
\mathrm{~d} f=4\end{array}$ \\
\hline Number of pairs & 40 & 40 & 40 \\
\hline
\end{tabular}

of this study was to determine the duration for the onset of action of lignocaine used as a topical anesthetic agent both in gel and spray form.

Although a variety of topical anesthetics are currently available, lignocaine was used in our study. Lignocaine is a gold standard to which all other drugs are compared and any allergy to lignocaine is very rare. 'Lignocaine gel and spray are most commonly used for

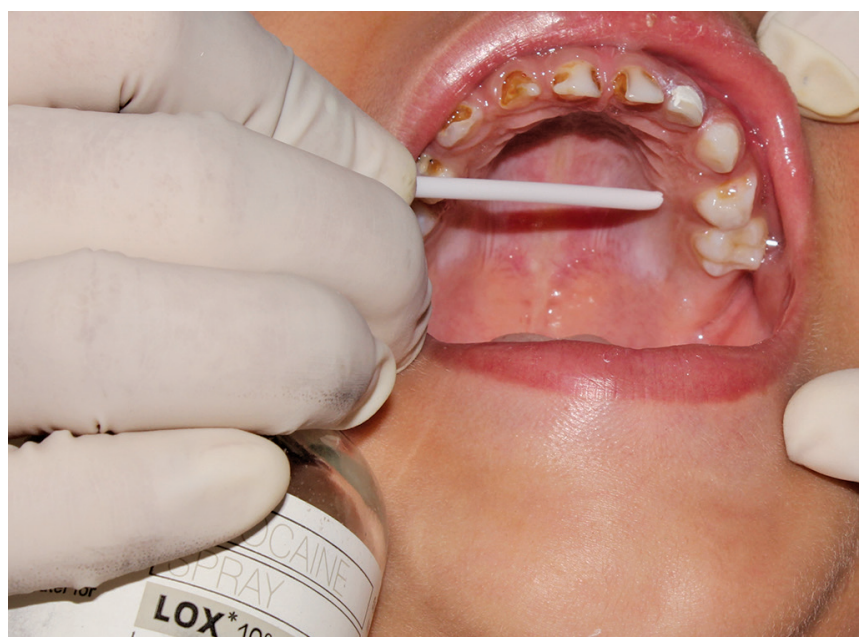

Fig. 6: Application of spray on the palate prior to local anesthesia administration 
topical anesthesia. Lignocaine gel $2 \%$ was used in this study as it is water soluble and penetrates the tissue more efficiently than the base form which is poorly water soluble (Fig. 5). A metered spray was used for lignocaine so as to control the amount of topical anesthetic delivered (Fig. 6).

The palatal site was chosen for our study as it is considered to be the most painful site for dental injections because there is a potential for the injection needle to contact the periosteum. The firmly attached keratinized tissue may inhibit tissue distention making palatal injections painful. ${ }^{11}$ This study was a split-mouth study and, hence, has the advantage of eliminating discrepancy which would have been obvious if two different subjects were selected.

The measurement of pain as an absolute value is difficult because it is different for different individuals, based on their subjective tolerance. However, there are studies that have found the VAS scale to be more sensitive than other pain scales and it can discriminate between small changes in the intensity of pain. ${ }^{12-14}$ Therefore, the VAS scale was used to measure subjective pain. However, to avoid any bias, the SEM scale was used to measure objective pain.

In the present study, the VAS score for lignocaine gel was the greatest after 30 seconds and the least after 3 minutes with not much difference between 1 and 3 minutes. The SEM score was the greatest after 30 seconds and the same after 1 and 3 minutes.

In the present study, the VAS score for lignocaine spray was the greatest after 30 seconds and the least after 3 minutes with not much difference between 1 and 3 minutes. The SEM score was the greatest after 30 seconds and the least after 1 minute. The scoring was greater for 3 minutes compared to 1 minute. The reasons for this could be the inability to keep the surface dry for a prolonged period of 3 minutes. It could also be due to anxiety building up in the child during a waiting period of 3 minutes. Similar to our study, Gill and Orr have demonstrated topical anesthetic to be ineffective if left for a period of only 30 seconds. Studies have shown that there was no benefit in keeping topical anesthetic beyond 2 minutes. ${ }^{15}$ But in contrast to our study, Stern and Giddon ${ }^{16}$ showed that application of the topical anesthetic to the mucous membrane for at least 2-3 minutes leads to profound soft tissue analgesia. Bagesund ${ }^{3}$ in his study had shown that the mean value of VAS score was similar after 2.5, 5, and 15 minutes after application of topical anesthesia. The least amount of time in their study was 2.5 minutes.

In all the groups, VAS and SEM scores were higher in patients treated with the lignocaine gel compared to the lignocaine spray concluding that the lignocaine spray was better than the lignocaine gel unanimously.

\section{Conclusion}

Lignocaine spray is more effective than lignocaine gel as a topical anesthetic agent.
Topical anesthetic action will be ineffective if left for a period of only 30 seconds.

There is not much difference after a waiting period of 1 minute or 3 minutes.

It can be concluded that the waiting period of 1 minute will achieve profound anesthesia.

\section{References}

1. Malamed SF. Handbook of local anesthesia, 5th ed., Elsevier Health Sciences, 2008; pp. 55-80.

2. Meechan JG. Intra-oral topical anesthetics: a review. J Dent 2000 Jan 31;28(1):3-14. DOI: 10.1016/S0300-5712(99)00041-X.

3. Bågesund $M$, Tabrizi P. Lidocaine $20 \%$ patch vs Lidocaine $5 \%$ gel for topical anesthesia of oral mucosa. Int J Paediatr Dent 2008 Nov 1;18(6):452-460. DOI: 10.1111/j.1365-263X.2007.00910.x.

4. Primosch RE, Rolland-Asensi G. Comparison of topical EMLA $5 \%$ oral adhesive to benzocaine $20 \%$ on the pain experienced during palatal anesthetic infiltration in children. Paediatr Dent 2001;23(1):11-14.

5. Kleinknecht RA, Klepac RK, et al. Origins and characteristics of fear of dentistry. J Am Dent Assoc 1973 Apr 1;86(4):842-848. DOI: 10.14219/ jada.archive.1973.0165.

6. Gale EN. Fears of the dental situation. J Dent Res 1972 Jul 1;51(4): 964-966. DOI: 10.1177/00220345720510044001.

7. Ram D, Peretz B. Administering local anaesthesia to Paediatric dental patients - current status and prospects for the future. Int J Paediatr Dent 2002 Mar 1;12(2):80-89. DOI: 10.1046/j.1365-263X.2002. 00343.x.

8. Rai K, Hegde AM, et al. Comparative evaluation of the efficacy of lignocaine and benzocaine patches for various dental treatment in children. Nitte Univ J Health Sci 2014 Mar 1;4(1):28.

9. Ngan KK, Richard Crout DM, et al. A survey of local and topical anesthesia use by pediatric dentists in the United States. Paediatr Dent 2001;23(3):265-269.

10. Gill CJ, Orr DL. A double-blind crossover comparison of topical anesthetics. J Am Dent Assoc 1979 Feb 1;98(2):213-214. DOI: 10.14219/ jada.archive.1979.0476.

11. Primosch RE, Robinson L. Pain elicited during intraoral infiltration with buffered Lidocaine. Am J Dent 1996 Feb;9(1):5-10.

12. Revill SI, Robinson JO, et al. The reliability of a linear analogue for evaluating pain. Anaesthesia 1976 Nov 1;31(9):1191-1198. DOI: 10.1111/j.1365-2044.1976.tb11971.x.

13. Seymour RA. The use of pain scales in assessing the efficacy of analgesics in postoperative dental pain. Eur J Clin Pharmacol 1982 Sep 1;23(5):441-444. DOI: 10.1007/BF00605995.

14. McGrath PA. An assessment of children's pain: a review of behavioral, physiological and direct scaling techniques. Pain $1987 \mathrm{Nov}$ 1;31(2):147-176. DOI: 10.1016/0304-3959(87)90033-9.

15. Bhalla J, Meechan JG, et al. Effect of time on clinical efficacy of topical anesthesia. Anesth Prog 2009 Jun;56(2):36-41. DOI: 10.2344/00033006-56.2.36.

16. Stern I, Giddon DB. Topical anesthesia for periodontal procedures. Anesth Prog 1975 Jul;22(4):105. 